University of Nebraska - Lincoln

DigitalCommons@University of Nebraska - Lincoln

Faculty Publications: Department of

Entomology

Entomology, Department of

2008

Inheritance of Cry1F resistance in laboratory-selected European

corn borer and its survival on transgenic corn expressing the

Cry1F toxin

E. J. G. Pereira

University of Nebraska-Lincoln

N. P. Storer

Dow AgroSciences LLC

Blair D. Siegfried

University of Nebraska-Lincoln, bsiegfried1@ufl.edu

Follow this and additional works at: https://digitalcommons.unl.edu/entomologyfacpub

Part of the Entomology Commons

Pereira, E. J. G.; Storer, N. P.; and Siegfried, Blair D., "Inheritance of Cry1F resistance in laboratory-selected European corn borer and its survival on transgenic corn expressing the Cry1F toxin" (2008). Faculty Publications: Department of Entomology. 166.

https://digitalcommons.unl.edu/entomologyfacpub/166

This Article is brought to you for free and open access by the Entomology, Department of at DigitalCommons@University of Nebraska - Lincoln. It has been accepted for inclusion in Faculty Publications: Department of Entomology by an authorized administrator of DigitalCommons@University of Nebraska - Lincoln. 


\title{
Inheritance of Cry1F resistance in laboratory-selected European corn borer and its survival on transgenic corn expressing the Cry1F toxin
}

\author{
E.J.G. Pereira ${ }^{1 \dagger}$, N.P. Storer ${ }^{2}$ and B.D. Siegfried ${ }^{1 *}$ \\ ${ }^{1}$ Department of Entomology, University of Nebraska, Lincoln, NE 68583: \\ ${ }^{2}$ Dow AgroSciences LLC, 9330 Zionsville Rd., Indianapolis, IN 46268
}

\begin{abstract}
A major assumption of the high-dose/refuge strategy proposed for insect resistance management strategies for transgenic crop plants that express toxins from Bacillus thuringiensis is that resistance traits that evolve in pest species will be recessive. The inheritance of Cry1F resistance and larval survival on commercially available Cry1F corn hybrids were determined in a laboratory-selected strain of European corn borer, Ostrinia nubilalis (Hübner), displaying more than 3000-fold resistance to Cry1F. Concentration-response bioassays of reciprocal parental crosses indicated that the resistance is autosomal and recessive. Bioassays of the backcross of the $F_{1}$ generation with the selected strain were consistent with the hypothesis that a single locus, or a set of tightly linked loci, is responsible for the resistance. Greenhouse experiments with Cry1F-expressing corn hybrids indicated that some resistant larvae survived the high dose of toxin delivered by Cry1F-expressing plants although $F_{1}$ progeny of susceptible by resistant crosses had fitness close to zero. These results provide the first direct evidence that the high dose/refuge strategy currently in place to manage resistance in Cry1F-expressing corn is appropriate.
\end{abstract}

Keywords: Bt corn, Ostrinia nubilalis, genetic crosses, on-plant survival, high-dose refuge strategy, resistance management

(Accepted 31 January 2008)

\section{Introduction}

First commercialised in 1996, transgenic plants expressing insecticidal proteins from the bacterium Bacillus thuringiensis $(B t)$ have generally been associated with reduced use of broad-spectrum insecticides (Shelton et al., 2002; Mendelsohn et al., 2003), thereby reducing the risk

\footnotetext{
*Author for correspondence

Fax: 001 (402) 472-4687

E-mail: bsiegfried1@unl.edu

${ }^{\dagger}$ Current address: Departmento de Ciencias Agrarias, Campus Rio Paranaiba, Universidade Federal de Vicosa, Rio Paranaiba, MG 38810, Brazil.
}

of these compounds to human health and the environment. Corn (Zea mays L.) is one of the crop plants that has been genetically modified to express $B t$ genes and provides protection from herbivorous insect pests (Koziel et al., 1993; Moellenbeck et al., 2001).

The European corn borer, Ostrinia nubilalis (Hübner) (Lepidoptera: Crambidae), is one of the most destructive pests of corn in the United States and Europe. In most of the US Corn Belt, O. nubilalis is a bivoltine insect-pest that causes significant economic losses by infesting whorl- and reproductive-stage corn and has been the target of several different management strategies (Hudon et al., 1989; Mason et al., 1996). In 2003, Cry1F-expressing corn hybrids (Chambers et al., 1991), derived from genetic transformation event TC1507 (see profile at http://www.agbios.com), were 
commercially deployed in the US for control of European corn borer. Cry1F-expressing corn hybrids, as well as other $B t$ expressing hybrids, represent an important alternative to conventional insecticides in terms of environmental safety and have increasingly been shown to have negligible effects on non-target organisms (Hellmich et al., 2001; Shelton et al., 2002; Naranjo et al., 2005).

Although genetically modified plants producing their own protective insecticides provide an important new approach to insect control, there is a concern that a largescale deployment of transgenic crops expressing insecticidal proteins could rapidly lead to the development of $B t$ resistance within pest populations (Andow \& Hutchison, 1998; ILSI, 1998; Ferré \& Van Rie, 2002; Shelton et al., 2002; Glaser \& Matten, 2003). The impact of insects developing resistance to corn hybrids expressing a $B t$ protein could include reduced yields, a return to reliance on more environmentally disruptive control options and potential resistance to related $B t$ proteins that comprise active ingredients of sprayable formulations. Reducing the risk of resistance evolution and developing sustainable pest management strategies remains a high priority.

In order to delay the evolution of insect resistance, adoption of appropriate resistance management strategies is necessary. Among the theoretical strategies for resistance management, the high-dose/refuge and pyramiding of more than one toxin with different target sites have been most widely cited (Roush, 1997, 1998; Gould, 1998; Zhao et al., 2003). With the high-dose/refuge approach, a high expression level of the insecticidal protein is intended to reduce the fitness of heterozygotes such that the inheritance of resistance is functionally recessive. This high dose must be combined with a refuge from exposure in order to maintain a pool of susceptible homozygotes that mate with rare individuals that are homozygous for resistance. Assuming that the resistance is functionally recessive, the heterozygous progeny are susceptible to the high-dose expression. A major assumption of the high-dose/refuge approach is that resistance is a recessive trait such that heterozygotes are susceptible to the high doses of toxin delivered by the transgenic plants. Although the high-dose/refuge strategy currently in place to manage resistance in $B t$ corn has been widely adopted, empirical data that validate this approach are generally lacking.

Well-characterised resistant strains provide a means to validate proposed resistance management strategies (Shelton et al., 2000; Zhao et al., 2003; Morin et al., 2004). Laboratoryselected strains that exhibit high levels of resistance to a toxin are especially useful in validating and improving resistance management strategies when the genetic architecture of resistance in those strains is similar to that expected to evolve under field conditions.

Although high levels of resistance to Cry $1 \mathrm{Ab}$ and formulated $B t$ toxins have been selected for, under laboratory conditions in a number of O. nubilalis colonies (Huang et al., 1997; Bolin et al., 1999; Chaufaux et al., 2001; Siqueira et al., 2004) to date there have been no reports that these colonies survive on Cry1Ab-expressing plants. In the present study, we report results of experiments designed to characterise a resistant strain of $O$. nubilalis that was selected in the laboratory for high levels of resistance to Cry1F (Pereira et al., 2008). The inheritance of the resistance and the ability of susceptible, resistant and F1 progeny to survive on transgenic plants was determined. The results of this research have direct implications for resistance management of $O$. nubilalis to Cry1F corn.

\section{Materials and methods}

Insect strains

The Cry1F-selected strain was initially developed by Mycogen Seeds (B. Lang, personal communication) and originated from a population derived from field collections at ten geographically distinct locations within the central US Corn Belt in 1996. A total of 115 females and 135 males were combined into one mating cage. The resulting offspring were used to establish a laboratory strain that was maintained using standard rearing techniques (Lewis \& Lynch, 1969) with slight modifications (Siqueira et al., 2004). Briefly, larvae were reared at $27 \pm 0.7^{\circ} \mathrm{C}$ and $80 \%$ $\mathrm{RH}$ under a 24-h photophase on a wheat germ-based diet. Pupae were transferred to mating cages and held under 16-h photophase. Egg masses were deposited onto waxed paper lining the top of the cage, gathered daily and incubated in Petri dishes lined with moistened filter paper until hatching.

Selection for Cry1F resistance was initiated in 1998 after the colony had been reared for seven generations under laboratory conditions. The conditions for rearing and selection methods are described in Pereira et al. (2008). Briefly, the Cry1F toxin used for selection was produced through fermentation of recombinant Pseudomonas fluorescens, strain MR872, and consisted of a proteolytically activated and chromatographically purified toxin (provided by Dow AgroSciences LLC, Indianapolis, IN). The $O$. nubilalis strain was selected with increasing concentrations of Cry1F incorporated into the rearing diet for 30 generations and then maintained at $35 \mu \mathrm{g} \mathrm{ml} \mathrm{m}^{-1}$ for ten generations. During 2001 and 2002, the colony was transferred to the University of Nebraska, where further selection was conducted using Cry1F from the same source used from 1998-2001 but applied to the surface of artificial diet with exposure of neonates for seven days and then transferring surviving larvae to untreated diet (Pereira et al., 2008). After generation 53, maintenance of the Cry1F-selected strain was achieved by exposing neonates to $60 \mathrm{ng} \mathrm{cm}^{-2}$, which corresponds to the upper limit of the $95 \%$ confidence interval of the concentration that kills $99 \%$ of the individuals (LC $\mathrm{L}_{99}$ ) from susceptible populations (B. Siegfried, personal communication). This maintenance selection was applied every three generations to eliminate any susceptible individuals remaining in the population.

The susceptible strain used for genetic crosses and survival experiments was derived from the Cry1F-selected strain after the first 30 generations of selection before resistance was fixed. Neonates were exposed to a low concentration of Cry1F on the diet $\left(2 \mathrm{ng} \mathrm{cm}^{-2}\right.$, equivalent to half of the $\mathrm{LC}_{50}$ for susceptible populations) for seven days. Individual larvae that had not initiated feeding and had not grown beyond first instar were transferred to rearing diet in the absence of toxin and used to initiate the susceptible colony. Subsequently, three more rounds of this process of selection for susceptibility were conducted. This method proved to increase susceptibility and decrease genetic variance of the strain, as indicated by lower lethal concentrations and steeper slopes in the probit regression of 
concentration-mortality curves compared with other susceptible strains (B.D.S., unpublished data).

\section{Analysis of inheritance}

Mass reciprocal crosses between selected and control strains were conducted, and the response of $F_{1}$ and backcross progeny to the Cry1F toxin was evaluated. The reciprocal crosses were repeated twice in two different generations. Backcross progeny were produced by mass crossing of $\mathrm{F}_{1}$ obtained from reciprocal crosses to the selected strain. To generate virgin males and females for the reciprocal crosses, corn borer pupae were separated by gender, and 150 Cry1F-selected females were pooled with 150 control males, and 150 control females were pooled with 150 Cry1F-selected males in mating cages. These crosses provided enough offspring for bioassays and backcross with the selected strain. To obtain the backcross generation, the two $F_{1}$ progenies (from mass crosses between selected and control strains) were combined, reared, sexed and crossed with the selected strain using the same procedure for reciprocal crosses.

$F_{1}$ and backcross progenies were tested for susceptibility to Cry1F using the standard bioassays developed in our laboratory (Marçon et al., 1999). The Cry1F toxin used for bioassays was the same used in the selection experiments. Briefly, the susceptibility of neonates to Cry1F was determined by exposure to varying concentrations of toxin applied on the surface of artificial diet. A single neonate ( $<24$-h after eclosing) was placed in each well of a 128-well tray (CD International, Pitman, NJ) and held for seven days at $27^{\circ} \mathrm{C}, 24$-h scotophase, and $80 \% \mathrm{RH}$ until larval mortality was recorded (Marçon et al., 1999). Dilutions were prepared in $0.1 \%$ Triton-X 100; bioassays were conducted in duplicate on two dates and included at least seven concentrations of purified toxin plus a control $(0.1 \%$ Triton- $X 100$ applied to the diet surface). Larval mortality was recorded after seven days of exposure.

Concentration-mortality data were analyzed by probit regression using POLO-PC (LeOra Software, 1987) to generate lethal concentrations and to determine significance of differences among strains and generations. A likelihood ratio test was conducted at $\alpha=0.05$ to determine the significance of resistance ratios and compare dose-response curves from the reciprocal crosses (Russell et al., 1977; Preisler et al., 1990). Dominance of resistance was calculated using the formula $D_{X}=\left(X_{R S}-X_{S S}\right) /\left(X_{R R}-X_{S S}\right)$, where $X_{R R}, X_{R S}$ and $X_{S S}$ are the quantitative values for a trait $X$ (i.e. $\log L C_{50}$ ) for resistant homozygotes, heterozygotes and susceptible homozygotes, respectively (Bourguet et al., 2000). However, because the resistant strain did not exhibit significant mortality at the highest Cry1F concentration tested, a low-end estimate of the $\mathrm{LC}_{50}$ was used for dominance calculations based on the highest concentration tested. The monogenic inheritance model was tested directly by using the Chi-square test to compare observed and expected mortality of the backcross progeny at different Cry1F concentrations (Preisler et al., 1990; Tabashnik, 1991; Tabashnik et al., 1992). If the resistance is monogenic, a backcross of $\mathrm{F}_{1}(\mathrm{SS} \times \mathrm{RR}) \times \mathrm{RR}$ will produce progeny that are $50 \%$ RS and $50 \%$ RR. To test this hypothesis, the expected mortality in the backcross progeny at toxin concentration $\mathrm{x}$ was calculated using the formula $Y_{X}=0.50\left(M_{R S}+M_{R R}\right)$, where $M_{R S}$ and $M_{R R}$ are the mortalities of the presumed
RS $\left(\mathrm{F}_{1}\right)$ and RR (Cry1F-sel. parental strain) genotypes at concentration $\mathrm{x}$, respectively.

\section{On-plant assays}

Greenhouse experiments were carried out with a commercially available Cry1F-expressing hybrid (Event TC1507) and its near isoline in the vegetative (V6-9) and reproductive (R1-3) stages. These stages were chosen to represent those that coincide with infestations of the 1st and 2nd $O$. nubilalis generations common to bivoltine populations that occur throughout most of the US Corn Belt (Hudon et al., 1989; Mason et al., 1996). Six overall treatment combinations were tested in a factorial design that involved two corn hybrids (Event TC1507 that expresses Cry1F and a near isoline) and three $O$. nubilalis genotypes (the Cry1Fselected and control strains assumed to be homozygous for resistance and susceptibility, respectively, and the hybrid $F_{1}$ progeny derived from reciprocal crosses between susceptible and resistant adults). To generate the $F_{1}$ progeny, corn borer pupae were separated by gender, and 100 Cry1F-selected females were pooled with 100 control males, and 100 control females were pooled with 100 Cry1Fselected males in mating cages. Because concentrationmortality data from the inheritance analysis indicated that resistance is autosomal, the progeny of the reciprocal crosses were pooled by combining the egg masses produced in each mating cage.

The experiments were carried out in a greenhouse at the University of Nebraska, Lincoln, NE, in 2003 and 2004. Seeds of TC1507 and its isoline were provided by Dow AgroSciences LLC, Indianapolis, IN. The corn hybrids were planted in a soil mixture composed of $50 \%$ black soil, $30 \%$ peat and 20\% sand in 18.9-1 pots using three seeds per pot. Two weeks later, the plants were thinned to a single plant per pot, which were then watered daily and fertilised as needed until reaching the appropriate phenological stage for infestation. The vegetative- and reproductive-stage experiments were conducted separately. In each experiment, the six treatments were randomly assigned to six areas in the greenhouse, and 30 plants of each hybrid were utilised for corn borer infestations (ten plants per treatment). The greenhouse was divided into six areas with a 2-m aisle separating the areas to reduce the risk of larvae moving among treatments. The TC1507 plants were tested for toxin expression with TraitCheck ${ }^{\mathrm{TM}}$ Bt1F Lateral Flow Kit (Strategic Diagnostics Inc., Newark, DE). Plants were infested (40 neonates per plant) by placing a $1.5-\mathrm{ml}$ microfuge tube containing the neonates one leaf below either the whorl (V8 stage) or the primary ear (R1 stage) (Ritchie et al., 1992; Mason et al., 1996). All plants were dissected 15 days after infestations to record survival and determine larval weight.

The data were analyzed as a randomised complete block design with years 2003 and 2004 as block factors using a two-way analysis of variance (ANOVA), with corn borer genotypes (RR, RS and SS) and corn hybrids (Herculex and Isoline) as the main factors. Percent survival was arcsine transformed and weight of survivors were log transformed before each ANOVA was performed to meet the assumptions of normality and homogeneity of variance (PROC UNIVARIATE, PROC GPLOT) (SAS Institute, 2002). Differences among means in each corn stage were tested using 


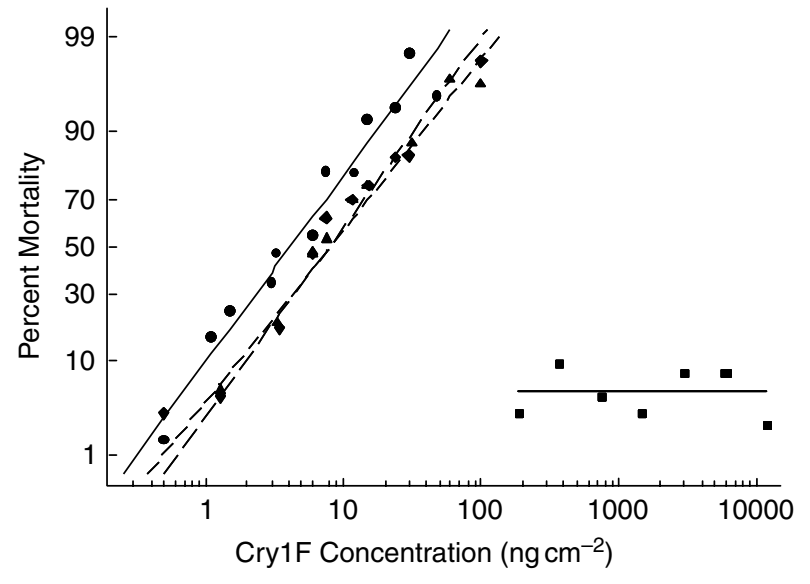

Fig. 1. Concentration-mortality curves of the progeny derived from reciprocal crosses of the Cry1F-selected and control $O$. nubilalis strains compared with the parental strains (-0, SS parents; -- --, SS Male $\times$ RR Female; - - -- , SS Female $\times$ RR Male; - - -, RR Parents).

Fisher's protected least significant difference (PROC MIXED) (SAS Institute, 2002).

Dominance of Cry1F resistance at the toxin concentration expressed by Cry1F corn $\left(D_{X}\right)$ was determined using formulas described by Bourguet et al. (2000) and methods adapted from Liu \& Tabashnik (1997). Values of $D_{X}$ range from zero (completely recessive resistance) to one (completely dominant resistance). When $D_{X}$ is 0.5 , resistance is referred to as codominant or additive. The traits used in the calculation of dominance were larval survival, percentage of weight gain 15 days after infestation and the combination of the two traits. The fitness of resistant homozygotes on Cry1Fexpressing corn was defined as one. Fitness of susceptible homozygotes was estimated as the phenotypic value of a trait for Cry1F-selected larvae divided by the phenotypic value of the trait for control larvae. Likewise, fitness of heterozygotes was estimated as the phenotypic value of a trait for $F_{1}$ progeny divided by the phenotypic value of the trait for Cry1F-selected larvae. For each corn borer genotype, survival on Cry1F corn was estimated by adjusting for mortality on non-expressing plants using Abbott's correction, and percentage of weight gain was calculated relative to the larval weight of each genotype on control corn. To take into account the fact that Cry1F corn may affect the survival and weight gain of the larvae, we combined these two components of fitness by multiplying their genotypic values and proceeded as above for calculation of dominance.

\section{Results}

\section{Inheritance of Cry1F resistance}

The progeny of resistant females crossed with susceptible males displayed response curves nearly identical to those of the progeny of susceptible females crossed with resistant males (fig. 1). When tested for equality of slopes and intercepts, the concentration-mortality curves for the two reciprocal crosses were not significantly different $\left(\chi_{1}^{2}=1.60\right.$, $P=0.450)$, indicating that resistance was autosomally inherited with no maternal effects. The response of the $F_{1}$ generation was similar to that of the control strain, indicating

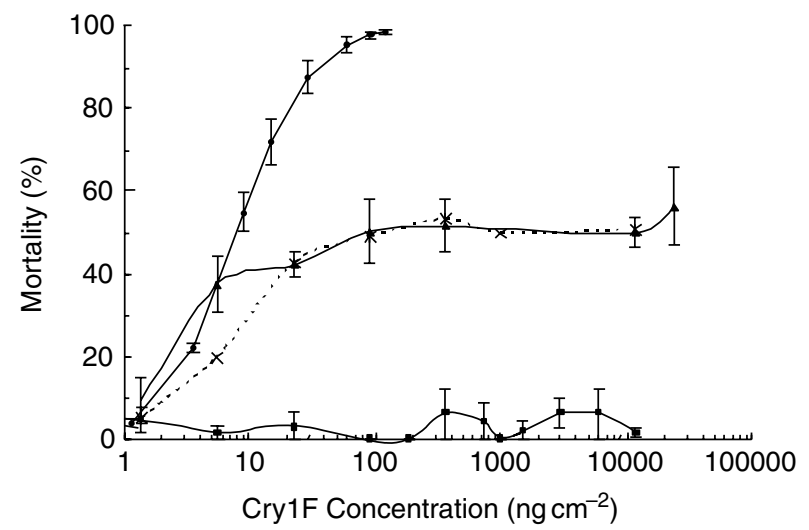

Fig. 2. Response curves of the backcross progeny compared with those of the $F_{1}(R S)$ and resistant (RR) parents. Error bars represent standard errors of the mean mortality attained at each concentration of Cry1F applied (--, RS parents; $-\mathbf{\Delta -}, \mathrm{RS} \times \mathrm{RR}$ progeny; - - -, RR parents; - - - $\times---$, expected RS $\times$ RR).

recessive resistance (fig. 1 ). The regression lines of the $F_{1}$ and control strain were parallel $\left(\chi_{1}^{2}=1.72, P=0.423\right)$, indicating that the phenotypic distance between heterozygous and homozygous susceptible individuals was constant over the range of Cry1F concentrations tested. Although we could only determine a lower limit for the $\mathrm{LC}_{50}$ of the selected strain, calculated dominance based on the methods proposed by Bourguet et al. (2000) indicates a dominance level $\left(D_{L C}\right)$ less than 0.11 , which is consistent with recessive inheritance.

Monogenic versus the polygenic inheritance models were tested by backcrossing the $\mathrm{F}_{1}$ generation with the selected strain and comparing the progeny's response with that of the parents. If resistance is conferred by a single locus or set of tightly linked loci, when the heterozygotes $F_{1}$ (RS) are backcrossed to the resistant strain (RR), the resulting progeny will consist of a 1:1 ratio of RS:RR genotypes. Since there was no mortality of the resistant parental strain at the highest concentrations used, a plateau at 50\% mortality of the backcross progeny is expected if the resistance is conferred by a single genetic factor. Such a plateau was apparent in the backcross generation, suggesting that half of backcross progeny responded to concentrations of Cry1F that kill heterozygotes while the other half did not (fig. 2). Additionally, the Chi-square test showed no significant departure from the expected ratio for a single factor inheritance $\left(\chi_{6}^{2}=8.39, P=0.211\right)$. Therefore, the pattern of response obtained in the backcross is consistent with simple monogenic inheritance of resistance.

\section{Survival on Cry1F corn}

Results of on-plant assays conducted with greenhousegrown vegetative and reproductive stage plants are presented in figs 3 and 4, respectively. Throughout these tests, the Cry1F-selected and control O. nubilalis strains as well as the progeny of crosses between the two strains effectively colonised non- $B t$ corn, as indicated by relatively high survival rates and larval weight of survivors 15 days after infestation (figs 3 and 4). 
a

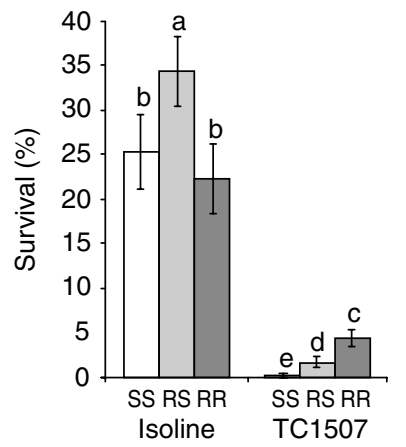

b

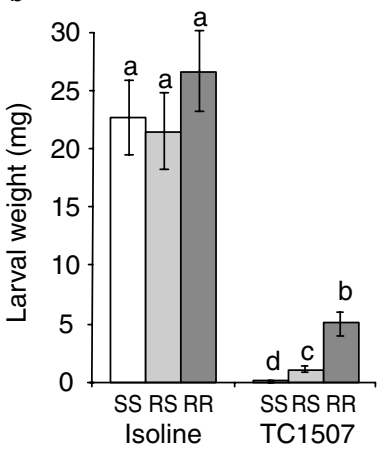

Corn hybrids and $O$. nubilalis genotypes a

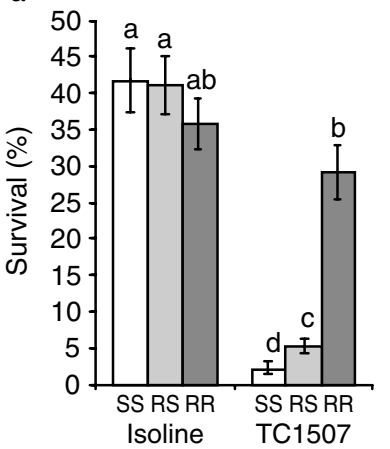

b

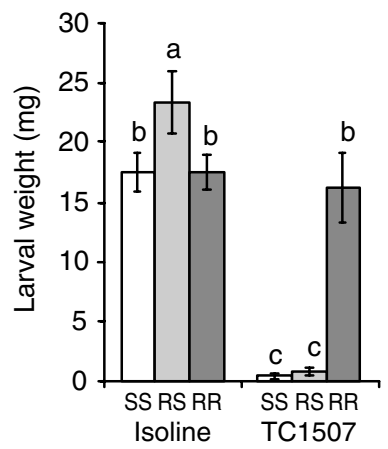

Fig. 3. Greenhouse tests with corn plants in the vegetative stage. (a) Percentage of survival and (b) larval weight of European corn borers homozygous for susceptibility to Cry1F (SS), heterozygous for Cry1F resistance (RS) and homozygous for Cry1F resistance (RR) after 15 days feeding on vegetative stages of Cry1F-expressing corn plants (event TC1507) and their nonCry1F, isoline counterparts. Error bars represent standard errors. Bars in a chart followed by the same letter are statistically similar (Fisher's protected LSD, $P>0.05$ ).

\section{Vegetative stages}

Comparisons of $O$. nubilalis larval survival and weight 15 days after infestation of whorl-stage corn are presented in fig. 3. Despite the almost complete insensitivity to Cry1F displayed by the selected strain in laboratory bioassays, survivorship of the selected strain on Cry1F-expressing corn plants (mean $\pm \mathrm{SEM}=4.3 \pm 0.9 \%$ ) was only $19 \%$ of that obtained on control plants $(22.3 \pm 4.0 \%)$. Survival rates of susceptible homozygotes (i.e. control larvae) were not statistically different from zero on Cry1F-expressing plants $(t=1.0, n=20, P=0.165)$. On Cry1F corn, significantly more $\mathrm{F}_{1}$ progeny (i.e. heterozygotes) survived relative to control larvae, although their weight was significantly reduced relative to resistant larvae on Cry1F-expressing plants (fig. 3b).

\section{Reproductive stages}

Figure $4 \mathrm{a}, \mathrm{b}$ depicts survival rates and weights of larvae surviving on control and Cry1F corn infested during the reproductive stage. In contrast to results from vegetativestage plants, larvae of the selected strain released on Cry1Fexpressing plants displayed survival rates and larval weights similar to those released on isoline plants. Susceptible and $F_{1}$ progeny larvae, however, were highly affected by the high dose of toxin delivered by Cry1F corn, as indicated by their relatively low survival rates and larval weights on transgenic plants. On Cry1F corn, larvae heterozygous for resistance survived slightly more than susceptible homozygotes despite the similarity of larval weight of the two genotypes.

\section{Dominance}

Assessment of dominance at the toxin concentration delivered by Cry1F corn showed that the resistance was

Fig. 4. Greenhouse tests with corn plants in the reproductive stage. (a) Percentage of survival and (b) larval weight of European corn borers homozygous for susceptibility to Cry1F (SS), heterozygous for Cry1F resistance (RS) and homozygous for Cry1F resistance (RR) after 15 days feeding on reproductive stages of Cry1F-expressing corn plants (event TC1507) and their non-Cry1F, isoline counterparts. Error bars represent standard errors. Bars in a chart followed by the same letter are statistically similar (Fisher's protected LSD, $P>0.05$ ).

functionally recessive as the estimates were less than 0.5 (table 1). Based solely on larval survival or weight gain as fitness components, resistance was more recessive in the reproductive stage than in the vegetative stage of Cry1F corn (table 1). However, when survival and weight gain were jointly considered, dominance values approached zero for both stages of plant development.

\section{Discussion}

Results of this research confirm that the high level of resistance to Cry1F present in our laboratory-selected strain of O. nubilalis (Pereira et al., 2008), considered the highest level of resistance to a $B t$ toxin ever reported for $O$. nubilalis (Huang et al., 1997; Bolin et al., 1999; Chaufaux et al., 2001; Siqueira et al., 2004), enabled our Cry1F-selected strain to feed on tissues of reproductive-stage Cry1F corn and to develop to late-instars displaying body mass similar to European corn borers feeding on non-Bt corn (see fig. 4). These results suggest that the laboratory-selected strain may be able to complete development on late-stage Cry1F corn, which makes it particularly relevant for refining resistance management recommendations for $O$. nubilalis to Cry $1 \mathrm{~F}$ corn.

When feeding on a Cry1F-expressing corn hybrid, O. nubilalis larvae heterozygous for Cry $1 \mathrm{~F}$ resistance exhibited survival rates and larval weights more similar to the susceptible homozygotes than the resistant homozygotes, especially on reproductive stage corn plants (see figs 3 and 4, table1). Assessment of dominance levels at the toxin concentration expressed by Cry1F corn revealed that resistance was indeed functionally recessive as estimates were less than 0.5 (table 1). Based solely on survival or weight gain as fitness components, the resistance expressed by the selected strain was more recessive for the reproductive stage than for the vegetative stage of Cry1F corn plants (figs 3 and 4, table 1). This result must be interpreted with 
Table 1. Dominance of Cry1F resistance in $O$. nubilalis on transgenic corn expressing Cry1F.

\begin{tabular}{|c|c|c|c|c|}
\hline Corn stage & O. nubilalis strain & Phenotypic value & Fitness $^{\mathrm{a}}$ & Dominance $^{\mathrm{b}}$ \\
\hline \multicolumn{5}{|c|}{ Percentage of larval survival } \\
\hline \multirow[t]{3}{*}{ Vegetative } & Control & 0.8 & 0.041 & \multirow[t]{3}{*}{0.23} \\
\hline & $\mathrm{F}_{1}$ & 5.0 & 0.257 & \\
\hline & Selected & 19.3 & 1 & \\
\hline \multirow[t]{3}{*}{ Reproductive } & Control & 5.3 & 0.065 & \multirow[t]{3}{*}{0.10} \\
\hline & $\mathrm{F}_{1}$ & 12.9 & 0.159 & \\
\hline & Selected & 81.3 & 1 & \\
\hline \multirow{4}{*}{ Vegetative } & Perce & ge of weight gain & & \multirow{4}{*}{0.27} \\
\hline & Control & 0.4 & 0.020 & \\
\hline & $\mathrm{F}_{1}$ & 5.3 & 0.281 & \\
\hline & Selected & 18.8 & 1 & \\
\hline \multirow[t]{3}{*}{ Reproductive } & Control & 2.6 & 0.028 & \multirow[t]{3}{*}{0.01} \\
\hline & $\mathrm{F}_{1}$ & 3.6 & 0.039 & \\
\hline & Selected & 92.8 & 1 & \\
\hline \multirow{4}{*}{ Vegetative } & Larval surviv & nd weight gain cor & & \multirow{4}{*}{0.07} \\
\hline & Control & 0.0 & 0.001 & \\
\hline & $\mathrm{F}_{1}$ & 0.3 & 0.072 & \\
\hline & Selected & 3.6 & 1 & \\
\hline \multirow[t]{3}{*}{ Reproductive } & Control & 0.1 & 0.002 & \multirow[t]{3}{*}{0.00} \\
\hline & & 0.5 & 0.006 & \\
\hline & Selected & 75.4 & 1 & \\
\hline
\end{tabular}

$\mathrm{F}_{1}$ is the hybrid progeny pooled from the two reciprocal mass crosses between the two parental strains, control and Cry1F selected.

For each corn borer genotype, survival on Cry1F corn was estimated by adjusting for mortality on non-Cry1F, control corn using Abbott's correction; percentage of weight gain was calculated relative to the larval weight of each genotype on control corn.

${ }^{\text {a }}$ Fitness is the phenotypic value of a trait (survival, weight gain, or both) for the larvae divided by the phenotypic value of the trait for Cry1F-selected larvae (see Materials and Methods).

${ }^{\mathrm{b}}$ Dominance can vary from zero (completely recessive resistance) to one (completely dominant resistance) (see Materials and Methods).

caution since the survival and weight of resistant larvae on vegetative-stage, Cry1F corn were quite low (fig. 3), which may have affected the phenotypic distances among the three genotypes (Bourguet et al., 2000). When larval survival and weight gain were jointly considered, dominance values and the relative fitnesses of the heterozygotes were almost zero for both corn stages tested. This result suggests that the resistance is functionally recessive or, more specifically, that heterozygotes have fitness very close to zero at the high dose of Cry1F delivered by transgenic corn plants. This functionally-recessive pattern of resistance supports the high-dose/refuge approach currently in place to manage resistance to Cry1F-expressing corn (Roush, 1997; Bates et al., 2005).

Despite the high level of resistance exhibited by the selected strain, as demonstrated by its virtual insensitivity to Cry1F in laboratory bioassays, larval survival on vegetative stage plants was only $20 \%$ of that on non-expressing $B t$ plants (see fig. 3), suggesting that Cry1F expression in green tissues is high enough to render the resistance functionally recessive (Carrière \& Tabashnik, 2001). In terms of resistance management recommendations for Cry $1 \mathrm{~F}$ corn, this result suggests that even if survivors from the previous season mate with each other, producing resistant progeny, fitness will be reduced by the high dose of toxin delivered by vegetative-stage plants, thereby slowing resistance evolution. This finding, along with the evidence of recessive resistance demonstrated in our survivorship tests, indicate that the high-dose/refuge strategy is likely to function effectively to delay the evolution of $O$. nubilalis resistance to Cry $1 \mathrm{~F}$ corn, provided that compliance with the refuge requirements exists, and the frequency of the resistance allele is low in the field.

Survival of heterozygotes on transgenic plants has been measured with Plutella xylostella in transgenic broccoli, expressing either Cry1Ac (Metz et al., 1995; Tang et al., 2001) or Cry1Ca (Zhao et al., 2000), and with Pectinophora gossypiella in transgenic cotton, expressing Cry1Ac (Liu et al., 1999). In all three cases, the effective or functional dominance of resistance was zero, which is consistent with the results of the present study. Huang et al. (2002) conducted tests with the Dipel-selected strain of $O$. nubilalis and concluded that resistant larvae were unable to establish reproducing populations on corn hybrids expressing Cry1Ab. Also, there was no evidence that the Cry1Ab-selected strains (Chaufaux et al., 2001; Siqueira et al., 2004) had enough resistance to survive on tissues of commercial Bt corn (B. Siegfried, personal communication). Therefore, to our knowledge, this study is the first to show the potential of $O$. nubilalis to develop levels of resistance high enough to survive on $B t$ plants and the recessive nature of the resistance on $B t$ corn.

The inheritance of resistance to Cry1F indicates that it is governed by a single, recessive, autosomal gene. This mode of inheritance is common in instances of 'Mode 1' (Van Rie et al., 1990; Tabashnik et al., 1997, 1998; Gahan et al., 
2001; Morin et al., 2003) resistance to B. thuringiensis toxins (Ferré \& Van Rie, 2002), but it contrasts with the intermediate resistance of Cry1Ab-selected O. nubilalis (Alves et al., 2006) and the dominant resistance observed in another strain of O. nubilalis resistant to Dipel, a multi-toxin formulation of B. thuringiensis (Huang et al., 1999). The genetic dominance observed in the Dipel-resistant strain, however, was expressed over a relatively low range of toxin concentrations; at high doses all individuals are expected to be susceptible. In our bioassays, heterozygotes for Cry1F resistance responded in a manner similar to the susceptible homozygotes, and this result is supported by the functionally recessive resistance observed in survivorship tests conducted with greenhouse grown plants.

Although no indication of reduced growth and asynchronous development of resistant homozygotes and heterozygotes relative to susceptible homozygotes were observed in control corn (as indicated by their similar if not greater larval weight in figs 3 and 4), it is important to investigate the existence of fitness costs associated with resistance. Comparison of fitness traits, such as development time, fecundity and longevity (Siegfried et al., 2001) in the susceptible and resistant strains, as well as the $F_{1}$ hybrid progeny, should provide valuable information for resistance management. If Cry1F resistance involves alteration in target sites of the toxin, as has been reported in the majority of the cases of Bt resistance (Ferré \& Van Rie, 2002), such alterations can lead to disruptive effects on behaviors and traits related to phenology (Carrière et al., 1994).

In summary, this research shows that our Cry1F-selected strain developed a high level of resistance and survived on commercially available transgenic corn expressing the Cry1F toxin. However, progeny resulting from crosses of resistant and susceptible individuals had fitness close to zero on these plants. This result provides evidence that the resistance is functionally recessive and indicates that the high-dose/ refuge strategy in place to manage $O$. nubilalis resistance to Cry1F corn is appropriate. The availability of this selected strain will provide an opportunity to determine the biochemical and molecular base of the resistance, which will provide further information to assist in the development of resistance management of $O$. nubilalis to Cry1F corn.

\section{Acknowledgements}

We thank Terence Spencer for assisting with surface selection, insect rearing and bioassays. We also thank Prof. Lance Meinke for the greenhouse space used for the on-plant survivorship tests. Funding for this research was provided by Dow AgroSciences LLC. A fellowship for E. Pereira was provided by the Brazilian Ministry of Education through the CAPES Foundation.

\section{References}

Alves, A.P., Spencer, T.A., Tabashnik, B.E. \& Siegfried, B.D. (2006) Inheritance of resistance to the Cry1Ab Bacillus thuringiensis toxin in Ostrinia nubilalis (Lepidoptera: Crambidae). Journal of Economic Entomology 99, 494-501.

Andow, D.A. \& Hutchison, W.D. (1998) Bt-corn resistance management. pp. 19-66 in Mellon, M. \& Rissler, J. (Eds)
Now or Never: Serious New Plans to Save a Natural Pest Control. Cambridge, MA, Union of Concerned Scientists.

Bates, S.L., Zhao, J.Z., Roush, R.T. \& Shelton, A.M. (2005) Insect resistance management in GM crops: past, present and future. Nature Biotechnology 23, 57-62.

Bolin, P.C., Hutchison, W.D. \& Andow, D.A. (1999) Long-term selection for resistance to Bacillus thuringiensis Cry1Ac endotoxin in a Minnesota population of European corn borer (Lepidoptera: Crambidae). Journal of Economic Entomology 92, 1021-1030.

Bourguet, D., Genissel, A. \& Raymond, M. (2000) Insecticide resistance and dominance levels. Journal of Economic Entomology 93, 1588-1595.

Carrière, Y. \& Tabashnik, B.E. (2001) Reversing insect adaptation to transgenic insecticidal plants. Proceedings of the Royal Society of London, Series B: Biological Sciences 268, 14751480.

Carrière, Y., Deland, J.P., Roff, D.A. \& Vincent, C. (1994) Lifehistory costs associated with the evolution of insecticide resistance. Proceedings of the Royal Society of London, Series B: Biological Sciences 258, 35-40.

Chambers, J.A., Jelen, A., Gilbert, M.P., Jany, C.S., Johnson, T.B. \& Gawronburke, C. (1991) Isolation and characterization of a novel insecticidal crystal protein gene from Bacillus thuringiensis subsp. aizawai. Journal of Bacteriology 173, 39663976.

Chaufaux, J., Seguin, M., Swanson, J.J., Bourguet, D. \& Siegfried, B.D. (2001) Chronic exposure of the European corn borer (Lepidoptera: Crambidae) to CrylAb Bacillus thuringiensis toxin. Journal of Economic Entomology 94, 15641570.

Ferré, J. \& Van Rie, J. (2002) Biochemistry and genetics of insect resistance to Bacillus thuringiensis. Annual Review of Entomology 47, 501-533.

Gahan, L.J., Gould, F. \& Heckel, D.G. (2001) Identification of a gene associated with $B t$ resistance in Heliothis virescens. Science 293, 857-860.

Glaser, J.A. \& Matten, S.R. (2003) Sustainability of insect resistance management strategies for transgenic Bt corn. Biotechnology Advances 22, 45-69.

Gould, F. (1998) Sustainability of transgenic insecticidal cultivars: integrating pest genetics and ecology. Annual Review of Entomology 43, 701-726.

Hellmich, R.L., Siegfried, B.D., Sears, M.K., Stanley-Horn, D.E., Daniels, M.J., Mattila, H.R., Spencer, T., Bidne, K.G. \& Lewis, L.C. (2001) Monarch larvae sensitivity to Bacillus thuringiensis-purified proteins and pollen. Proceedings of the National Academy of Sciences of the United States of America 98, 11925-11930.

Huang, F.N., Higgins, R.A. \& Buschman, L.L. (1997) Baseline susceptibility and changes in susceptibility to Bacillus thuringiensis subsp. kurstaki under selection pressure in European corn borer (Lepidoptera: Pyralidae). Journal of Economic Entomology 90, 1137-1143.

Huang, F., Buschman, L.L., Higgins, R.A. \& McGaughey, W.H. (1999) Inheritance of resistance to Bacillus thuringiensis toxin (Dipel ES) in the European corn borer. Science 284, 965-967.

Huang, F.N., Buschman, L.L., Higgins, R.A. \& Li, H. (2002) Survival of Kansas Dipel-resistant European corn borer (Lepidoptera: Crambidae) on Bt and non-Bt corn hybrids. Journal of Economic Entomology 95, 614-621.

Hudon, M., LeRoux, E.J. \& Harcourt, D.G. (1989) Seventy years of European corn borer (Ostrinia nubilalis) research in North America. Agricultural Zoology Reviews 3, 53-96. 
ILSI - International Life Sciences Institute (1998) An Evaluation of Insect Resistance Management in Bt Field Corn: A Science-based Framework for Risk Assessment and Risk Management. 85 pp. Washington, DC, ILSI.

Koziel, M.G., Beland, G.L., Bowman, C., Carozzi, N.B., Crenshaw, R., Crossland, L., Dawson, J., Desai, N., Hill, M., Kadwell, S., Launis, K., Lewis, K., Maddox, D., Mcpherson, K., Meghji, M.R., Merlin, E., Rhodes, R., Warren, G.W., Wright, M. \& Evola, S.V. (1993) Field Performance of elite transgenic maize plants expressing an insecticidal protein derived from Bacillus thuringiensis. Nature Biotechnology 11, 194-200.

LeOra Software (1987) POLO-PC: A User's Guide to Probit and Logit Analysis. 22 pp. Berkeley, CA.

Lewis, L.C. \& Lynch, R.E. (1969) Rearing the European corn borer, Ostrinia nubilalis (Hübner), on diets containing corn leaf and wheat germ. Iowa State Journal of Science 44, 9-14.

Liu, Y.B. \& Tabashnik, B.E. (1997) Inheritance of resistance to the Bacillus thuringiensis toxin Cry1C in the diamondback moth. Applied and Environmental Microbiology 63, 22182223.

Liu, Y.B., Tabashnik, B.E., Dennehy, T.J., Patin, A.L. \& Bartlett, A.C. (1999) Development time and resistance to Bt crops. Nature 400, 519.

Marçon, P.C.R.G., Young, L.J., Steffey, K.L. \& Siegfried, B.D. (1999) Baseline susceptibility of European corn borer (Lepidoptera: Crambidae) to Bacillus thuringiensis toxins. Journal of Economic Entomology 92, 279-285.

Mason, C.E., Rice, M.E., Calvin, D.D., Van Duyn, J.W., Showers, W.B., Hutchison, W.D., Witkowski, J.F., Higgins, R.A., Onstad, D.W. \& Dively, G.P. (1996) European Corn Borer - Ecology and Management. 57 pp. Ames, IA, Iowa State University.

Mendelsohn, M., Kough, J., Vaituzis, Z. \& Matthews, K. (2003) Are Bt crops safe? Nature Biotechnology 21, 1003-1009.

Metz, T.D., Roush, R.T., Tang, J.D., Shelton, A.M. \& Earle, E.D. (1995) Transgenic broccoli expressing a Bacillus thuringiensis insecticidal crystal protein - implications for pest resistance management strategies. Molecular Breeding 1, 309-317.

Moellenbeck, D.J., Peters, M.L., Bing, J.W., Rouse, J.R., Higgins, L.S., Sims, L., Nevshemal, T., Marshall, L., Ellis, R.T., Bystrak, P.G., Lang, B.A., Stewart, J.L., Kouba, K., Sondag, V., Gustafson, V., Nour, K., Xu, D.P., Swenson, J., Zhang, J., Czapla, T., Schwab, G., Jayne, S., Stockhoff, B.A., Narva, K., Schnepf, H.E., Stelman, S.J., Poutre, C., Koziel, M. \& Duck, N. (2001) Insecticidal proteins from Bacillus thuringiensis protect corn from corn rootworms. Nature Biotechnology 19, 668-672.

Morin, S., Biggs, R.W., Sisterson, M.S., Shriver, L., Ellers-Kirk, C., Higginson, D., Holley, D., Gahan, L.J., Heckel, D.G., Carriere, Y., Dennehy, T.J., Brown, J.K. \& Tabashnik, B.E. (2003) Three cadherin alleles associated with resistance to Bacillus thuringiensis in pink bollworm. Proceedings of the National Academy of Sciences of the United States of America 100, 5004-5009.

Morin, S., Henderson, S., Fabrick, J.A., Carrière, Y., Dennehy, T.J., Brown, J.K. \& Tabashnik, B.E. (2004) DNA-based detection of Bt resistance alleles in pink bollworm. Insect Biochemistry and Molecular Biology 34, 1225-1233.

Naranjo, S.E., Head, G. \& Dively, G.P. (2005) Field studies assessing arthropod nontarget effects in Bt transgenic crops: introduction. Environmental Entomology 34, 11781180.

Pereira, E.J.G., Lang, B.A., Storer, N.P. \& Siegfried, B.D. (2008) Selection for Cry1F resistance in the European corn borer and cross resistance to other Cry toxins. Entomologia Experimentalis et Applicata 126, 115-121.

Preisler, H.K., Hoy, M.A. \& Robertson, J.L. (1990) Statistical analysis of modes of inheritance for pesticide resistance. Journal of Economic Entomology 83, 1649-1655.

Ritchie, S.W., Hanway, J.J. \& Benson, G.O. (1992) How a Corn Plant Develops, Special Report. 48 pp. Ames, IA, Iowa State University.

Roush, R.T. (1997) Bt-transgenic crops: just another pretty insecticide or a chance for a new start in resistance management? Pesticide Science 51, 328-334.

Roush, R.T. (1998) Two-toxin strategies for management of insecticidal transgenic crops: can pyramiding succeed where pesticide mixtures have not? Philosophical Transactions of the Royal Society of London, Series B: Biological Sciences 353, 1777-1786.

Russell, R.M., Robertson, J.L. \& Savin, N.E. (1977) POLO: a new computer program for probit analysis. Bulletin of the Entomological Society of America 23, 209-213.

SAS Institute. (2002) SAS User's Manual. version 9.1 Cary, NC, SAS Institute.

Shelton, A.M., Tang, J.D., Roush, R.T., Metz, T.D. \& Earle, E.D. (2000) Field tests on managing resistance to Bt-engineered plants. Nature Biotechnology 18, 339-342.

Shelton, A.M., Zhao, J.Z. \& Roush, R.T. (2002) Economic, ecological, food safety, and social consequences of the deployment of Bt transgenic plants. Annual Review of Entomology 47, 845-881.

Siegfried, B.D., Zoerb, A.C. \& Spencer, T. (2001) Development of European corn borer larvae on Event 176 Bt corn: influence on survival and fitness. Entomologia Experimentalis et Applicata 100, 15-20.

Siqueira, H.A.A., Moellenbeck, D., Spencer, T. \& Siegfried, B.D. (2004) Cross-resistance of Cry1Ab-selected Ostrinia nubilalis (Lepidoptera: Crambidae) to Bacillus thuringiensis delta-endotoxins. Journal of Economic Entomology 97, 10491057.

Tabashnik, B.E. (1991) Determining the mode of inheritance of pesticide resistance with backcross experiments. Journal of Economic Entomology 84, 703-712.

Tabashnik, B.E., Schwartz, J.M., Finson, N. \& Johnson, M.W. (1992) Inheritance of resistance to Bacillus thuringiensis in diamondback moth (Lepidoptera: Plutellidae). Journal of Economic Entomology 85, 1046-1055.

Tabashnik, B.E., Liu, Y.B., Finson, N., Masson, L. \& Heckel, D.G. (1997) One gene in diamondback moth confers resistance to four Bacillus thuringiensis toxins. Proceedings of the National Academy of Sciences of the United States of America 94, 1640-1644.

Tabashnik, B.E., Liu, Y.B., Malvar, T., Heckel, D.G., Masson, L. \& Ferre, J. (1998) Insect resistance to Bacillus thuringiensis: uniform or diverse? Philosophical Transactions of the Royal Society of London, Series B: Biological Sciences 353, 1751-1756.

Tang, J.D., Collins, H.L., Metz, T.D., Earle, E.D., Zhao, J.Z., Roush, R.T. \& Shelton, A.M. (2001) Greenhouse tests on resistance management of Bt transgenic plants using refuge strategies. Journal of Economic Entomology 94, 240-247.

Van Rie, J., Mcgaughey, W.H., Johnson, D.E., Barnett, B.D. \& Vanmellaert, H. (1990) Mechanism of Insect resistance to 
the microbial insecticide Bacillus thuringiensis. Science 247, $72-74$.

Zhao, J.Z., Collins, H.L., Tang, J.D., Cao, J., Earle, E.D., Roush, R.T., Herrero, S., Escriche, B., Ferre, J. \& Shelton, A.M. (2000) Development and characterization of diamondback moth resistance to transgenic broccoli expressing high levels of Cry1C. Applied and Environmental Microbiology 66, 3784-3789.

Zhao, J.Z., Cao, J., Li, Y.X., Collins, H.L., Roush, R.T., Earle, E.D. \& Shelton, A.M. (2003) Transgenic plants expressing two Bacillus thuringiensis toxins delay insect resistance evolution. Nature Biotechnology 21, 1493-1497. 